Rev. Latinoam. Psicopat. Fund., São Paulo, v. 14, n. 3, p. 566-570, setembro 2011

Obras completas de Sigmund Freud

Sigmund Freud

São Paulo: Companhia das Letras, 2010

\title{
Comentário sobre a tradução de Paulo César Souza das Obras completas de Sigmund Freud
}

Betty Bernardo Fuks

Em sua homenagem ao texto "A tarefa do tradutor" de Walter Benjamin, Jacques Derrida reinterpreta o mito bíblico da Torre de Babel para ilustrar o double bind, possibilidade/ impossibilidade, da tradução (Derrida, 2006). Para o filósofo da desconstrução, o pecado dos homens da tribo Shem (do hebraico, nome) foi o de querer impor seu nome e uma língua universal a todas as outras tribos. Com o objetivo de chegar aos céus para alcançar a soberania e exercer uma nova ordem, os homens pré-babélicos construíram uma torre, despertando a fúria divina. Num ataque de violência, gritando seu próprio nome Bavel ou Bavel, palavra do hebraico semelhante a "confusão", Deus destrói sumariamente a torre e estabelece a diferenciação entre os idiomas e a dispersão entre os povos. O homem ficou, assim, condenado a sofrer da confusão entre as múltiplas línguas do universo, sempre sujeitas à 
incompletude do trabalho de tradução. Um destino que limita a universalidade de uma língua: transparência proibida, univocidade impossível (Derrida, 2006, p. 25).

A razão pela qual resumo o ensaio de Derrida como intróito a este comentário, deve-se à acirrada polêmica estabelecida em torno do tema da tradução da obra de Freud em todos idiomas, principalmente neste momento em que ela entra em domínio público. Em se tratando da tradução da "língua freudiana", a maldição babélica parece ter recaído não apenas sobre a dificuldade de verter do alemão o soberbo estilo da escrita do pai da psicanálise, mas se estendeu, também, à especificidade da tradução de alguns dos mais importantes termos da teoria psicanalítica.

O caso da tradução das obras de Freud no Brasil é bastante particular: a primeira versão que dispomos foi feita pela editora Delta diretamente do francês e do espanhol. Já a editora Imago, nos anos 1960, usou a tradução inglesa feita enquanto Freud vivia e por ele acompanhada. Ou seja, às dificuldades descritas acima somaram-se os problemas da tradução indireta. Se a tarefa do tradutor é estar o mais próximo possível do original para exprimir, o mais próximo possível a relação íntima entre os idiomas, há que se apostar que novos tradutores se preocupem em sanar os erros e distorções que foram produzidos nas edições anteriores.

O trabalho é certamente árduo. Implica em traduzir direto do alemão e recuperar o vigor e clareza dos textos do criador da psicanálise, um dos grandes estilistas do século XX, qualidade pela qual recebeu o Prêmio Goethe. Rever expressões popularizadas que merecem novas traduções e, finalmente, não deixar de se inteirar sobre os estudos, ao longo destes cento e onze anos que nos separam de $A$ interpretação dos sonhos, e que enriqueceram a trama conceitual de uma disciplina "sempre inacabada, pronta a deslocar as ênfases de suas teorias ou a modificá-las" (Freud, 1923, p. 248), porque marcada pela experiência clínica.

Portanto, é muito bem-vinda a escolha da Companhia das Letras de fazer traduzir Freud sob o comando de Paulo César Souza, conhecido como grande germanista preocupado com a substancial qualidade do escrito que traduz. Num país onde se traduz muitíssimo sem que os tradutores gozem, em geral, de prestígio, Paulo César é uma das exceções nesse panorama. Dono de uma invejável capacidade de traduzir, o que lhe valeu dois prêmios Jabuti pela tradução das obras de Nietzsche e de Brecht; o que significa que, para além de conhecer profundamente o alemão, escreve muito bem em nossa língua. O fato de já ter publicado um livro, As palavras de Freud, oriundo de sua tese de doutoramento, no qual perscruta o estilo e a terminologia freudianos, garante a qualidade da tradução e não deixa de ser um privilégio para o leitor que quer acompanhar os meandros da versão dos 20 volumes previstos para compor a edição brasileira, que têm como base a edição alemã das Gesammelte Werke (Obras completas). 
Em As palavras de Freud, Paulo César faz ouvir sua voz de tradutor fascinado por um escritor que frequenta a fronteira entre a linguagem científica e a comum, e expõe, simultaneamente, duas modalidades de apreensão do psiquismo que, em princípio, parecem absolutamente excludentes: a via da decifração de sentido e a via da energia ou economia psíquica. O leitor pode conhecer, em minúcias, as divergências e discordâncias de estudiosos que se dedicaram à linguagem freudiana, os bastidores da tradução da Standard Edition, e da nova edição francesa dos textos de Freud. Paulo César sustenta a ideia de que, para traduzir Freud, deve-se fugir da tentativa de diminuir o estilo de uma escrita imprecisa, com uma terminologia exagerada que amortizaria, fatalmente, a riqueza poética.

Assim, optou por manter-se fiel ao original, sem muitas interpretações ou interferências de comentaristas ou teóricos posteriores da psicanálise. Busca recriar, em português, o frescor da prosa freudiana, na intenção de levar o leitor a compreender certos aspectos do pensamento de Freud que ficam obscurecidos pelas más traduções precedentes e querelas terminológicas estabelecidas, segundo seu entendimento, pela "guerra" entre escolas. Se preocupa com o estilo do escritor e, de certa forma, recoloca uma certa ambiguidade própria da escrita adotada pelo pai da psicanálise que, todos sabem, era sempre regida por escolhas de palavras de uso corrente no alemão de sua época. O fato de que, em Freud, a fronteira entre uma linguagem científica especial e a linguagem comum é sempre móvel, teve um peso grande nas decisões de Paulo César.

Entretanto, sabemos que algumas das palavras de Freud foram elevadas à categoria de conceitos. O que onera o tradutor: deve cuidar dos aspectos estilísticos e literários da escrita freudiana e, ao mesmo tempo, estar atento à terminologia para evitar causar problemas na apreensão teórico-clínica da obra e dificultar a transmissão da psicanálise.

A questão é que Paulo César, como já dito, privilegia o ponto de vista estritamente literário. Confessa, na apresentação da edição, ter se aproximado do mestre de Viena pela via da linguagem e da literatura. Como linguista, está extremamente atento à arte de construir frases, de ordenar e combinar os termos harmoniosamente, enfim de cuidar da riqueza literária do que traduz. E neste sentido, sua escrita é primorosa. Decisões sobre passagens de versão problemática ou sobre termos técnicos de difícil tradução que por vezes podem, até mesmo, conforme faz notar, se modificar e adquirir nuanças de sentido segundo o contexto, são informadas em notas de rodapé de forma bastante esclarecedora. Vale ressaltar, neste momento, o trabalho da editora Schwarcz, a bela impressão dos volumes já lançados

Quando Freud se associa aos poetas e escritores, aqueles que "conhecem, entre o céu e a terra, muitas coisas que nossa sabedoria escolar ainda não pode 
imaginar" (Freud, 1907, p. 7), insere sua disciplina, definitivamente, na fronteira do discurso literário e do discurso poético. Assim, a psicanálise passou a ficar sob a jurisdição dos homens de letras e a sua própria trama conceitual, a metapsicologia, a bruxa que cozinha em fogo lento, entre outras coisas, o indecidível do Trieb, o conceito-limite entre o psíquico e o somático. Trieb, palavra que, conforme lembra Paulo Cesar, Freud dizia suscitar inveja em muitas línguas modernas, é o vocábulo da psicanálise que mais fomenta debates.

Nosso tradutor opta por traduzir Trieb pela palavra "instinto". Não concorda com o termo "pulsão", bastante usado no Brasil, dado a grande influência que sofremos da obra de Lacan. Em parte, devido ao fato de não concordar com o uso de neologismos quando é possível remarcar na língua portuguesa palavras que cobrem a mesma gama de sentidos presente no texto de Freud. Por outro lado, ao contrário dos intérpretes da obra freudiana que fazem uma diferença entre o uso das palavras "Trieb" e "Instinkt", tomando o primeiro por aquele que define o objeto da psicanálise por oposição ao instinto animal, objeto da biologia, Paulo César privilegia, em base a uma longa pesquisa, "a 'rede semântica' da palavra 'instinto' ligada aos campos léxicos de 'impulso', 'sexo', 'ímpeto' etc." (Souza, p. 258) e faz sua própria escolha.

Certamente a opção suscitará muitas discussões. Principalmente por parte dos psicanalistas que consideram traduzir Trieb por "instinto" uma tentativa de "biologizar" o aparelho psíquico freudiano e subtrair seu valor de conceito-limite, uma interface na problemática do dualismo corpo e psíquico, da disciplina que vive no "entre-dois"; a psicanálise frequenta vários campos do saber, ao mesmo tempo em que exige repensar todos eles.

Paulo faz ouvir versões do vocabulário freudiano sem pretender impô-las de modo absoluto. Reconhece, assim, que embora sua meta seja a de tentar reproduzir no português, dentro de suas possibilidades, os efeitos textuais do original, não pode nutrir ilusões de atingir uma transparência absoluta. Daí a escolha de verter alguns termos que lhe parecem melhores em nosso idioma, deixando ao leitor a sugestão de sentir-se à vontade para substituir mentalmente o que está lendo pela tradução a que está acostumado. Uma solução polissêmica que, sem dúvidas, revela a tensão entre a possibilidade e a impossibilidade de traduzir certos vocábulos da "língua freudiana".

Por fim, resta dizer que a fidelidade de Paulo César à letra de Freud, leva o leitor a experimentar o inquietante prazer que provoca o texto de qualquer grande escritor. Um compromisso que certamente lhe facilitou reconhecer, publicamente, o fato de que qualquer trabalho de tradução da obra do pai da psicanálise, por melhor que seja, não será jamais definitiva e muito menos perfeita. 


\section{Referências}

Derrida, J. Torres de Babel. Belo Horizonte: Editora da UFMG, 2006.

Freud, S. (1907). Delírios y sueños en la "Gradiva" de W. Jensen. In: Obras completas. Buenos Aires: Amorrortu, 1976.

SouzA, P.C. de. As palavras de Freud. O vocabulário freudiano e suas versões. São Paulo: Companhia das Letras, 2010.

\section{Betty Bernardo Fuks}

Doutora em Comunicação e Cultura pela Universidade Federal do Rio de Janeiro - UFRJ (Rio de Janeiro, RJ, Br); Psicanalista; Professora do Mestrado Profissional em Psicanálise, Saúde e Sociedade da Universidade Veiga de Almeida (Rio de Janeiro, RJ, Br); Pesquisadora do Conselho Nacional de Desenvolvimento Científico e Tecnológico - CNPq (Brasília, DF, Br); Membro da Associação Universitária de Pesquisa em Psicopatologia Fundamental (São Paulo, SP, Br); Autora de Freud e a judeidade; a vocação do exílio (Rio de Janeiro: Zahar, 2000).

Av. Rui Barbosa, 500/602

22250-020 Rio de Janeiro, RJ, Brasil

e-mail: betty_fuks@ @otmail.com 